\title{
FINANCIAMENTO E DEMOCRATIZAÇÃO DO ACESSO À EDUCAÇÃO SUPERIOR NO BRASIL: DA DESERÇÃO DO ESTADO AOO PROJETO DE REFORMA
}

\author{
Paulo Roberto Corbucci*
}

RESUMO: O presente texto aborda o financiamento da educação superior no Brasil, tendo como recorte temporal o início da década de 1990 até o presente. Parte-se do pressuposto de que esse período refletiu, em alguma medida, o esgotamento dos modelos político e econômico vigentes até a primeira metade dos anos de 1980, para se analisar o papel atribuído à educação superior nos programas de governo da década seguinte. Discorre sobre o avanço do setor privado a partir de meados dos anos de 1990, além de tratar da suposta dicotomia entre educação superior e educação básica. No que se refere ao financiamento stricto sensu, analisa a participação dos entes públicos e privados, e compara a situação brasileira com a de países da Organização para Cooperação e Desenvolvimento Econômico (OCDE). Ainda sobre o tema, analisa as possibilidades de autofinanciamento das instituiçóes federais de ensino superior, a partir de estudo de caso realizado no âmbito da Universidade de Brasília (UNB). Por fim, apresenta as primeiras medidas que integram a proposta de reforma da educação superior, que tem sido coordenada pelo Ministério da Educação (MEC). À guisa de conclusão, aventa possíveis implicaçōes e desdobramentos das políticas de financiamento da educação superior, implementadas nos últimos anos.

Palavras-chave: Educação superior. Financiamento e gastos. Democratização do acesso. Projeto de reforma.

\section{FINANCING AND DEMOCRATIZING THE ACCESS TO HIGHER EDUCATION IN BRAZIL: FROM STATE DESERTION TO THE REFORM PROJECT}

ABSTRACT: This text deals with the financing of higher education in Brazil, focusing on the period from the early 90s to present. It assumes that, to some extent, this period has reflected the collapse of

* Doutor em sociologia pela Universidade de Brasília (UNB), pesquisador do IPEA e professor da Universidade Católica de Brasília. E-mail: paulo.corbucci@ipea.gov.br 
Financiamento e democratização do acesso à educação superior no Brasil...

the political and economical models in force up to the mid-80s so as to analyze the role assigned to higher education in government programs from the following decade. It then discusses the advance of the private sector from the mid-90s onwards and the supposed dichotomy between higher education and basic schooling. With regard to stricto sensu financing, this paper analyses the share of public and private entities, respectively, and compares the Brazilian situation to that of other countries from the Organization for Economic Cooperation and Development (OECD). Furthermore, based on a case study carried out at the University of Brasília (UNB), it looks into the possibility of self-funding for Federal higher education institutions. Finally, it presents the first measures that integrate the higher education reform proposal coordinated by the Department of Education (MEC). As a conclusion, it foresees possible implications and shortcomings of the higher education financing policies implemented these last years.

Key words: Higher education. Financing and expenditure. Democratizing access. Reform project.

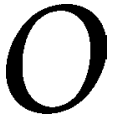

início dos anos de 1980 torna evidentes o esgotamento dos efeitos do milagre econômico brasileiro, que selou o fim da "legitimidade" do regime militar instaurado em 1964, bem como a revitalização dos movimentos sociais no país. A partir dessa nova conjuntura, a abertura política viabiliza-se, tendo como corolário a Constituição de 1988.

Curiosamente, os diversos avanços nos campos político e social, inseridos na nova Constituição, foram instituídos sob um contexto de retração da atividade econômica, que resultou na redução da capacidade de investimentos do Estado em todas as áreas e, em particular, na educação superior. Com isso, interrompe-se o processo de expansão física da rede federal de ensino superior que estava em curso até o final da década de 1970 .

\section{Educação superior nos programas de governo dos anos de 1990}

Em consonância com o discurso da modernização que pautou o projeto político do primeiro governo referendado pelas urnas, após o regime militar, caberia às instituições de ensino superior a formação de recursos humanos demandados por um mercado, cada dia 
mais competitivo, que se forjava a partir da almejada inserção do Brasil no chamado Primeiro Mundo.

No entanto, esse projeto modernizante, de orientação neoliberal, não continha, segundo o Movimento Docente (MD), uma proposta clara para a educação superior brasileira. $\mathrm{O}$ MD também ressaltava que, além de cortar gastos destinados ao setor, o governo federal estava suprimindo diversas conquistas trabalhistas, frutos de anos de diálogo com os dirigentes do Ministério da Educação (MEC).

Diante do aprofundamento do fosso entre as reivindicaçôes em prol de avanços das políticas educacionais e o projeto do governo, restava ao MD empenhar esforços no sentido de preservar as conquistas acumuladas ao longo de anos de mobilizações e negociações. Tratavase, pois, de resistir ao processo de sucateamento da educação pública (ANDES, 1990).

De acordo com o programa de governo do presidente Fernando Collor de Mello, o ensino superior brasileiro apresentava algumas distorções significativas: i) formação de profissionais desvinculada da geração de riquezas; ii) insuficiente formação na área de ciências exatas; e iii) gasto excessivo, em detrimento dos demais níveis de ensino.

Com vistas a superar os problemas identificados, foram estabelecidas cinco linhas de ação: i) ampliação do acesso; ii) respeito à autonomia universitária; iii) maior estímulo ao desenvolvimento de pesquisas entre universidades e empresas; iv) ampliação dos programas de pós-graduação; e v) capacitação e valorização dos profissionais de educação.

Quando se confrontam alguns dos problemas diagnosticados com as açôes propostas, tornam-se evidentes certas incoerências. Por exemplo, se os gastos com ensino superior consumiam a maior parcela do orçamento do MEC, como seria possível valorizar a carreira docente, no que concerne à sua remuneração, se as despesas de pessoal já correspondiam, em 1990, a $84 \%$ do orçamento global das instituições federais de ensino superior (IFES)?

$\mathrm{Na}$ prática, a intenção de valorização do magistério foi flagrantemente contrariada pelas ações efetivamente implementadas, a começar pelo fato de, em 1992, a participação das despesas com pessoal haverse reduzido a $75 \%$ dos gastos totais com as IFES, ao mesmo tempo em que também se reduzia o montante de recursos destinado a essas instituições. 
Financiamento e democratização do acesso à educação superior no Brasil...

Tal entendimento é referendado por Velloso (1992), quando afirma que o Governo Collor teria descumprido sistematicamente o preceito constitucional que determina à União a aplicação mínima, na área de educação, de $18 \%$ da arrecadação líquida de impostos. $\mathrm{O}$ autor argumenta ainda que as políticas públicas para o setor educacional não evidenciavam preocupação, seja com a expansão da matrícula ou com a melhoria da qualidade dos serviços ofertados.

Se o Governo Collor defendia, via discurso, a ampliação da oferta de vagas nas instituições públicas, desde o início de seu mandato favoreceu-se a expansão do ensino privado. Tal orientação esbarrou, no entanto, na própria estrutura interna do Estado, mais precisamente no órgão até então responsável pelo reconhecimento e credenciamento de cursos e instituições - o Conselho Federal de Educação (CFE).

Com a deposição do Governo Collor e a assunção de Itamar Franco, tem continuidade a disputa entre o Executivo federal e o CFE. Embora os documentos oficiais de governo tratassem de várias questôes relativas ao ensino superior brasileiro, boa parte das iniciativas governamentais concentrou-se no embate com aquele Conselho. Essa disputa passou por várias fases, sendo que a primeira delas correspondeu à decisão de que todas as resoluçóes aprovadas pelo Conselho deveriam passar pelo crivo do presidente da República. Num segundo momento, buscou-se limitar parte de seus poderes por meio da descentralização do processo decisório relativo à criação de instituições e à autorização de cursos. Com isso, a Ordem dos Advogados do Brasil e o Conselho Nacional de Saúde passaram a ter essa prerrogativa, respectivamente, com relação aos cursos de direito e medicina.

Posteriormente, é publicada exposição de motivos na qual se afirmava ser arcaica a estrutura do CFE, além de não estar sintonizada com as diretrizes da política nacional estabelecida pela Constituição de 1988. Neste sentido, o Conselho deveria ser reestruturado, de modo que se adequasse às novas demandas nacionais. Juntamente com a exposição de motivos, publica-se Medida Provisória extinguindo o CFE e institui-se uma comissão de transição, cuja atribuição seria a de formular diretrizes para o funcionamento do futuro Conselho Nacional de Educação (CNE). Entre as mudanças propostas estava a redução de seu poder decisório, de modo que o novo Conselho assumiria funções consultiva e de assessoramento ao MEC. 
A política do MEC para o ensino superior brasileiro, no Governo Fernando Henrique Cardoso, beneficiou-se das medidas adotadas nas gestôes anteriores, sobretudo no que se refere à extinção do $\mathrm{CFE}$, ocorrida no Governo Itamar Franco. A partir de então, o MEC delegou maior responsabilidade pela expansão do ensino superior à esfera privada, evidenciada pela ampliação considerável da participação desse setor na oferta de vagas.

O Plano Plurianual (PPA) 1996-1999, elaborado nesse governo, destacava dois pressupostos norteadores das ações na área da educação superior: i) contribuição do setor para a melhoria da qualidade do ensino; e ii) formação de recursos humanos qualificados para a modernização do país. Além disso, revelava preocupação com a necessidade de se criar um sistema de avaliação da qualidade do ensino ofertado, sobretudo o da esfera privada.

No capítulo referente à ciência e tecnologia (C\&T), reconhecia-se que o Brasil se encontrava em posição inteiramente desfavorável nessa área, comparativamente com outras nações. $\mathrm{O}$ país teria investido em C\&T, na década de 1980 , entre $0,6 \%$ e $0,8 \%$ do Produto Interno Bruto (PIB), ao passo que em países industrializados esse investimento correspondia a $3 \%$ do PIB. Desse modo, estabeleceu-se como meta de gastos em C\&T, para 1999, o equivalente a $1,5 \%$ do PIB.

As análises relativas aos investimentos em C\&T apontavam para a necessidade de se adquirir domínio no campo tecnológico, com vistas a preparar o país para a abertura da economia e sua conseqüente inserção no processo de globalização. Neste sentido, dever-se-ia enfatizar a formação de um corpo técnico apto a atender às demandas do desenvolvimento tecnológico.

A despeito dessas diretrizes políticas integrantes dos discursos oficiais, os dispêndios do MEC com a educação superior, em especial aqueles destinados à manutenção da rede federal, foram sistematicamente contingenciados ao longo da década de 1990. Além disso, sua composição foi bastante alterada, à medida que se ampliaram os gastos com inativos e pensionistas, e, conseqüentemente, reduziu-se a parcela destinada ao pagamento de pessoal ativo e aos investimentos em infra-estrutura. Ao se estrangular a capacidade de expansão das IFES, também se abriu caminho para o crescimento do setor privado. 
Financiamento e democratização do acesso à educação superior no Brasil...

\section{Fragilização das IFES e avanço do setor privado}

A incapacidade do poder público federal de ampliar os gastos em educação, ${ }^{1}$ em grande medida devida ao processo de ajuste fiscal dos anos de 1990, fez com que não se conseguisse atender plenamente à crescente demanda por educação superior. Esse processo de enfraquecimento do setor público federal foi um dos elementos centrais para a forte expansão na oferta de vagas e o aumento das matrículas no setor privado, favorecidos por certa desregulamentação do setor, no que se refere à flexibilização dos requisitos para a criação de cursos e instituições. Outra implicação da perda relativa de poder do papel desempenhado pela União refere-se à ampliação da participação dos estados, sobretudo aqueles de maior expressão econômica, e de alguns municípios, na oferta desse nível do ensino. ${ }^{2}$

Como já mencionado, a decisão do governo federal de extinguir o então Conselho Federal de Educação, e de instituir em seu lugar o Conselho Nacional de Educação, confere ao MEC maior autonomia na condução do processo de expansão do ensino de graduaçãa, ao assumir funções deliberativas, até então prerrogativas do CFE.

O objetivo principal dessa medida foi o de expandir a oferta de vagas sem, no entanto, ampliar a participação da rede federal e, conseqüentemente, dos gastos da União. Para tanto, foram acelerados e facilitados os processos de autorização, reconhecimento e credenciamento de cursos e instituiçōes do setor privado, por parte do CNE. Com isso, favoreceu-se consideravelmente a expansão desse nível do ensino, por intermédio da iniciativa privada.

Tendo em vista a orientação mais geral da política para o setor, foram definidos alguns mecanismos de avaliação do ensino de graduação, no intuito de monitorar sua qualidade, ou ao menos classificar os cursos oferecidos. Para tanto, foram instituídos o Exame Nacional de Cursos, ou "Provão", como ficou popularmente conhecido, e a Avaliação das Condições de Oferta de Cursos de Graduaçãao, posteriormente denominada Avaliação das Condições de Ensino.

Ao mesmo tempo o MEC instou as IFES a aumentarem a oferta de vagas, a partir de sua capacidade instalada, uma vez que os concursos públicos para docentes e servidores técnico-administrativos haviam sido suspensos, a despeito do substancial crescimento das aposentadorias ocorridas no período. A redução dos investimentos em infra-estrutura e capi- 
tal, registrada sobretudo a partir de 1995 , também pode ser vista como outro indício que reafirmava tal disposição do governo federal.

Conforme mostram os dados de matrícula nos cursos de graduação, fornecidos pelo próprio MEC, no período 1990/1997, a taxa de crescimento do setor público foi de $31,5 \%$, ao passo que no privado se limitou a 23,4\%. Porém, no biênio 1997/1998, o aumento das matrículas no setor privado já atingia $11,4 \%$. Desse momento em diante, as taxas anuais de crescimento oscilaram entre $15,7 \%$ e $17,5 \%$. Portanto, o incremento de matrículas, registrado em apenas um ano, aproximou-se daquele correspondente ao referido período de sete anos.

Desse modo, ampliou-se significativamente a participação da esfera privada no conjunto das matrículas nos cursos de graduação, invertendo a tendência identificada ao longo do período 1990/1994, cuja participação havia sofrido retração contínua (de $62,4 \%$ para $58,4 \%$ ), de forma que, em 2002, o setor privado já respondia por cerca de $70 \%$ do total de matrículas.

Apesar de o setor público não ter evidenciado o mesmo dinamismo expansionista, ao longo do período sob análise, houve considerável crescimento das matrículas no biênio 2001/2002 - cerca de $12 \%$. O melhor desempenho médio foi devido, principalmente, às IES estaduais, cuja taxa de crescimento (16,4\%) superou, inclusive, a das instituições privadas $(16,1 \%)$. Cabe também ressaltar o surpreendente aumento verificado entre as IES municipais $(31,8 \%)$, ainda que sua participação na matrícula total seja marginal $(3,0 \%)$.

A demanda por educação superior, medida pelo total de inscrições nos exames vestibulares, cresceu $161,6 \%$ entre 1990 e 2002 . No mesmo período, a oferta de vagas ampliou-se em 252,6\%. Com a expansão da oferta, reduziu-se a proporção de candidatos por vaga, de 3,8 para 2,8. No entanto, distintas tendências podem ser identificadas entre os setores público e privado. Se, para o primeiro, houve aumento significativo dessa relação (de 5,7 candidatos por vaga, em 1990, para 8,9 , em 2002), no ensino privado, além de essa proporção ter sido historicamente menor, também se verificou retração no mesmo período (de 2,9, para 1,6).

É possível que o maior índice de aproveitamento das vagas nas redes públicas e o correspondente decréscimo no âmbito das instituições privadas estejam associados à contração de renda da classe média, 
Financiamento e democratização do acesso à educação superior no Brasil...

ocorrida ao longo do período sob análise. Ao passo que nas primeiras a taxa se ampliou de $81,4 \%$, em 1990 , para 95,0\%, em 2002, no conjunto das instituiçõos privadas o movimento foi inverso: respectivamente, de $80,8 \%$ para $62,6 \%$.

Esses dados sugerem que o modelo de expansão do ensino superior, centrado na iniciativa privada, encontra limites que podem comprometer, em breve, a própria sustentabilidade da oferta, tendo em vista a capacidade de demanda da sociedade. Neste sentido, a ampliaçáo da oferta de vagas per se não constitui condição suficiente para assegurar a democratização do acesso à formação em nível superior.

No intuito de assegurar o preenchimento de parte das vagas ofertadas pelo setor privado, foi instituído, em 1999, o Fundo de Financiamento ao Estudante do Ensino Superior (FIES), destinado a alunos com certo nível de insuficiência econômica. Concebido para substituir o antigo Crédito Educativo, o FIES foi desenhado para tornar-se autofinanciável, ao contrário do que vinha ocorrendo com o antecessor. Apesar disso, ainda hoje a taxa de cobertura da população-alvo do programa se mantém bastante aquém da demanda, tanto pelo fato de sequer atender $10 \%$ do total de matriculados no setor privado como também por os índices de inadimplência haverem subido nos últimos anos.

\section{O falso dilema: educação superior ou educação básica?33}

$\mathrm{Na}$ segunda metade dos anos de 1990, diversas foram as iniciativas que visaram a desqualificar e deslegitimar a educação superior de caráter público, no Brasil, com argumentos que giravam em torno de sua ineficiência e elitização, bem como da descomunal desproporção entre o que o Estado despende, em termos per capita, com os diversos níveis de ensino.

Sabe-se que o gasto per capita na educação superior, em qualquer país do mundo, é sempre maior que aquele despendido com a educação básica. No caso brasileiro, essa diferença se torna ainda mais acentuada pelo fato de o montante destinado à educação básica ser insuficiente para garantir um ensino de qualidade. Desse modo, quando se compara essa despesa per capita com os dispêndios médios na educação superior, no Brasil, a conclusão precipitada a que se pode chegar é a de que estes gastos seriam exorbitantes e, mais que isso, incompatíveis com as condições sociais do país. 
O problema do financiamento da educação brasileira não reside no fato de o gasto com a educação superior ser excessivo, e sim em que os investimentos na educação básica são insuficientes. Ao analisar os dispêndios educacionais de nações integrantes da Organização para Cooperação e Desenvolvimento Econômico (OCDE), Almeida (2001) mostra que nesses países a proporção entre a despesa com a educação básica e a da educação superior é de 1 para 3 (respectivamente, R\$ 3.637 e $\mathrm{R}$ \$ 9.823), ao passo que no Brasil essa relação é de 1 para 14 ( $\mathrm{R} \$ 691$ no ensino fundamental e $\mathrm{R} \$ 9.756$ na educação superior).

A virtual transferência de recursos destinados ao financiamento da educação superior pública, em favor da educação básica, aponta para dois problemas cruciais. O primeiro, e talvez o mais grave, consiste no efeito contrário que tal medida se propõe a alcançar. Além do inevitável desmantelamento de um sistema que, reconhecidamente, oferta o ensino de melhor qualidade, tal medida reduziria as chances de ingresso aos mais pobres. ${ }^{4}$ Esse desmantelamento acarretaria prejuízos significativos para o desenvolvimento científico-tecnológico, na medida em que essa área se desenvolve predominantemente no âmbito das instituições de ensino superior (IES) públicas. É pouco provável que o desempenho dessa função estratégica para o desenvolvimento e a soberania nacionais possa ser assumido pelo setor privado, a não ser por intermédio de transferências e/ou subsídios governamentais. Impactos negativos também seriam sentidos na extensão universitária, principalmente com relação aos serviços prestados, pelos hospitais vinculados às IES, à população mais necessitada.

O segundo problema refere-se ao adicional de recursos que essa relocação incorporaria à educação básica. Mesmo que fossem integralmente canalizados para esse nível do ensino, ainda assim seriam insuficientes para assegurar as melhorias que se fazem necessárias, sobretudo se o montante limitar-se ao que o Ministério da Educação destina, atualmente, à manutenção das IFES, que em 2003 equivalia a 0,6\% do PIB. Conforme estimativas apresentadas no relatório do grupo de trabalho sobre financiamento da educação, caso se queira cumprir as metas do Plano Nacional de Educação (PNE), os gastos com a educação básica deverão elevar-se do patamar de 3,33\% do PIB, em 2003, para 6,52\%, em 2011. Portanto, a relação custo-benefício de um eventual desmantelamento das IFES não apenas traria prejuízos incomensuráveis para o país como também não resolveria a problemática que afeta a educação básica. 
Financiamento e democratização do acesso à educação superior no Brasil...

Torna-se difícil defender a qualidade da educação básica sem a proposição de uma educação superior também de qualidade, na medida em que, por exemplo, um dos fatores decisivos para se obter o primeiro intento consiste no tipo de profissional que irá atuar nesse nível do ensino. Para tornar-se técnica e politicamente capacitado para esse fim, o profissional deverá ter sólida formação, a qual constitui tarefa indelegável da educação em nível superior. Do mesmo modo, torna-se incoerente propor que o país ingresse na chamada sociedade do conhecimento, inclusive tendo-se como meta de governo o aumento dos gastos em ciência $\&$ tecnologia, ao mesmo tempo em que se afirma que são demasiados os dispêndios governamentais com as IES públicas, justamente onde é gerada a maior e mais relevante produção científica nacional, onde se forma a esmagadora maioria dos pesquisadores brasileiros. ${ }^{5}$

$\mathrm{O}$ argumento baseado na convicção de que as despesas do poder público com a educação superior são excessivas está referenciado em dados que não foram devidamente qualificados. Por exemplo, quando se obtém o gasto médio por estudante nas instituições federais, mediante a divisão dos dispêndios do MEC com a educação superior pelo total de estudantes de graduação matriculados nessas instituições, desconsidera-se a complexidade de serviços e produtos oferecidos pelas IFES à sociedade.

As obrigações previdenciárias também têm sido incluídas nesses gastos, como se estivessem interferindo nos níveis de cobertura e qualidade dos serviços e produtos ofertados. Quando se eliminam essas despesas, assim como as sentenças judiciais que se referem a passivos trabalhistas, e se faz uma ponderação do alunado atendido pelas IFEs, segundo o nível de ensino cursado, verifica-se que o gasto per capita nessas instituições é bastante heterogêneo.

Conforme mostra pesquisa realizada no âmbito do IPEA, ${ }^{6}$ o gasto médio por aluno, para o conjunto das universidades federais, em 1997, situava-se em R\$ 8,4 mil. No entanto, nas universidades que ofertavam apenas cursos em nível de graduação e que não mantinham hospitais universitários, o gasto por aluno não ultrapassava $\mathrm{R} \$$ 4,0 mil. Portanto, o gasto por aluno nas instituições que se limitam à oferta de ensino de graduação não difere do que é despendido por alunos matriculados em instituições privadas com perfil semelhante. Desse modo, não se sustenta o argumento de que é onerosa a manutenção das IES públicas, quando se compara esse gasto per capita nas universidades federais (UFs) com o valor médio nas instituiçóes privadas. 


\section{Financiamento público versus investimento privado}

Entre os países que integram a Organização para Cooperação e Desenvolvimento Econômico (OCDE), cerca de $78 \%$ dos gastos realizados com a educação superior, em 2000, eram de natureza pública. Mesmo aqueles membros reconhecidamente mais pobres, como México e Turquia, registravam índices acima desse valor médio.

A despeito da tendência identificada nesses países, considerados modelos de desenvolvimento socioeconômico, a opção assumida pelo Estado brasileiro, ao longo dos dois últimos mandatos presidenciais, foi a de transferir para o setor privado a tarefa de atender, de forma preponderante, a demanda por esse tipo de formação.

Apesar de o crescimento das matrículas nos cursos de graduação ter sido expressivo nos últimos anos, a política de expansão pela via privada já tem dado mostras de seus limites. A primeira delas refere-se ao crescimento expressivo do porcentual de vagas não preenchidas, conforme pode ser observado na Tabela 1. Outra evidência empírica dos limites da política encampada pelo MEC corresponde ao aumento dos índices de inadimplência dos estudantes matriculados nas instituiçôes privadas.

\section{Tabela 1}

(Taxas de ocupação de vagas no ensino de graduação: 1990-2002)

\begin{tabular}{|l|c|c|c|c|}
\hline \multicolumn{1}{|c|}{ IES } & 1990 & $\mathbf{1 9 9 5}$ & $\mathbf{1 9 9 9}$ & $\mathbf{2 0 0 2}$ \\
\hline Públicas & 81,4 & 88,7 & 96,3 & 95,0 \\
\hline Privadas & 80,8 & 81,5 & 78,7 & 62,6 \\
\hline
\end{tabular}

Fonte: INEP/MEC; elaboração própria.

O vertiginoso crescimento da participação do setor privado no financiamento da educação superior brasileira, ocorrido nos últimos anos, pode ser interpretado como ausência deliberada do Estado, à medida que este passou a reduzir os investimentos necessários não só à expansão do sistema como também à manutenção dos padrões de qualidade e excelência das IFES.

De acordo com estudo realizado pelo Instituto Nacional de Estudos Pedagógicos (INEP), ${ }^{7}$ os gastos estimados das três esferas públi- 
Financiamento e democratização do acesso à educação superior no Brasil...

cas com a educação superior, em 1999 , somaram cerca de $\mathrm{R} \$ 8,8$ bilhões. Nesse mesmo ano, havia mais de 1,5 milhão de estudantes de graduação matriculados em instituições privadas. Utilizando-se como parâmetro um gasto mensal per capita de $\mathrm{R} \$ 315,{ }^{8}$ estima-se que, naquele ano, os dispêndios privados tenham atingido a cifra aproximada de $\mathrm{R} \$ 5,8$ bilhões. Com base nessas estimativas, a participação do poder público no financiamento da educação correspondia, em 1999, a algo como $60 \%$ do total. Considerando-se que, nos últimos anos, o crescimento das matrículas no setor privado tem sido substancialmente maior que o da esfera pública, e que os gastos governamentais com a educação superior não foram ampliados, pode-se afirmar que atualmente a iniciativa privada já responde por mais de $50 \%$ dos recursos disponíveis a essa área, o que indica forte retração da participação do poder público no financiamento da educação superior brasileira. ${ }^{9}$

\section{Perspectivas de financiamento para as IFES}

Uma das questôes que integram o debate acerca do financiamento da educação superior no Brasil é a que trata da viabilidade da autonomia financeira das IFEs. No limite, questiona-se em que medida essas instituições teriam potencial de geração de recursos próprios em substituição àqueles tradicionalmente aportados pelo Estado. ${ }^{10}$

As IES públicas têm buscado alternativas variadas de captação de recursos como forma de complementar o orçamento do Tesouro. A prestação de serviços, a comercialização de bens e os projetos de cooperação têm sido formas bastante utilizadas por essas instituições na geração de receitas.

Apesar de o autofinanciamento estar sendo praticado em todo o país, esse instrumento tem sido objeto de críticas freqüentes, sob o argumento de que se constitui no primeiro passo para a privatização da educação superior pública. Em contrapartida, há os que defendem a geração de recursos próprios como importante fonte alternativa de financiamento para assegurar a sobrevivência da educação superior pública e gratuita.

Pesquisa realizada no âmbito do Instituto de Pesquisa Econômica Aplicada (IPEA), ${ }^{11}$ concluída em 2000, evidenciou que, a despeito da contenção orçamentária a que estiveram submetidas as universidades federais (UFs), na segunda metade da década de 1990, elas estariam apre- 
sentando melhorias em termos de desempenho e produtividade. Uma das questóes suscitadas a partir dos resultados do referido estudo foi a de como as UFs estariam superando as restriçõos financeiras, de modo que se assegurassem a expansão das vagas e o aumento da produção técnico-científica.

A questão foi investigada mediante a realização de estudo de caso, tendo como objeto a Universidade de Brasília (UNB). ${ }^{12} \mathrm{O}$ principal objetivo do estudo foi o de evidenciar as alternativas de financiamento praticadas por essa instituição, tendo em vista que, entre as IES federais, é a que responde pelo maior volume de recursos diretamente arrecadados, em termos relativos e absolutos. ${ }^{13}$

Conforme mostram os dados contidos nas tabelas 2 e 3, as 39 UFs então existentes, no período 1995/2002, tiveram gastos ampliados em $46,5 \%$, ao passo que o orçamento executado da UNB sofreu variação de $92,8 \%$.

\section{Tabela 2}

(Gastos realizados pelas universidades federais: 1995-1998)

\begin{tabular}{|l|r|r|r|r|r|}
\hline & \multicolumn{1}{c|}{1995} & \multicolumn{1}{c|}{1996} & \multicolumn{1}{c|}{1997} & \multicolumn{1}{c|}{1998} & 95/98 (var. \%) \\
\hline Universidades (a) & 5.415 .265 .258 & 5.402 .951 .219 & 5.739 .335 .828 & 5.832 .607 .016 & 7,7 \\
\hline UnB (b) & 192.881 .230 & 209.288 .051 & 232.358 .084 & 274.408 .021 & 42,3 \\
\hline b/a (\%) & 3,6 & 3,9 & 4,0 & 4,7 & \\
\hline
\end{tabular}

Fonte: SIAFI/SIDOR (em R $\$$ correntes); elaboração própria.

\section{Tabela 3}

(Gastos realizados pelas universidades federais: 1999-2002)

\begin{tabular}{|l|r|r|r|r|r|}
\hline & \multicolumn{1}{c|}{1999} & \multicolumn{1}{c|}{$\mathbf{2 0 0 0}$} & \multicolumn{1}{c|}{2001} & \multicolumn{1}{c|}{2002} & 99/02 (var. \%) \\
\hline Universidades (a) & 6.364 .055 .726 & 6.829 .107 .142 & 6.886 .833 .386 & 7.931 .532 .708 & 24,6 \\
\hline UnB (b) & 325.472 .652 & 376.626 .416 & 340.827 .762 & 371.869 .202 & 14,3 \\
\hline b/a (\%) & 5,1 & 5,5 & 4,9 & 4,7 & \\
\hline
\end{tabular}

Fonte: SIAFI/SIDOR (em R $\$$ correntes); elaboração própria.

Esse comportamento distinto foi devido em grande medida ao fato de a UNB ter ampliado a captação de recursos por intermédio das 
Financiamento e democratização do acesso à educação superior no Brasil...

chamadas fontes próprias. Tomando-se como exemplo a fonte 250 Recursos Diretamente Arrecadados -, verifica-se que as tendências assumidas pelo conjunto das universidades e pela UNB são opostas. Ao passo que as primeiras registraram decréscimo de $42,7 \%$ ao longo do período 1995/2002, na UNB essa fonte cresceu 314,8\%.

\section{Tabela 4}

(Gastos realizados pelas universidades federais sob a fonte 250: 1995-1998)

\begin{tabular}{|l|r|r|r|r|r|}
\hline & \multicolumn{1}{|c|}{1995} & \multicolumn{1}{c|}{1996} & \multicolumn{1}{c|}{1997} & \multicolumn{1}{c|}{1998} & 95/98 (var. \%) \\
\hline Universidades (a) & 446.467 .366 & 413.724 .058 & 389.682 .194 & 415.777 .550 & $(6,9)$ \\
\hline UnB (b) & 26.492 .333 & 45.628 .011 & 64.513 .823 & 70.626 .792 & 166,6 \\
\hline b/a (\%) & 5,9 & 11,0 & 16,6 & 17,0 & \\
\hline
\end{tabular}

Fonte: SIAFI/SIDOR (em R\$ correntes); elaboração própria.

\section{Tabela 5}

(Gastos realizados pelas universidades federais sob a fonte 250: 1999-2002)

\begin{tabular}{|l|r|r|r|r|r|}
\hline & \multicolumn{1}{|c|}{1 1999 } & \multicolumn{1}{c|}{$\mathbf{2 0 0 0}$} & \multicolumn{1}{c|}{ 2001 } & \multicolumn{1}{c|}{ 2002 } & 99/02 (var. \%) \\
\hline Universidades (a) & 222.530 .404 & 238.247 .189 & 259.349 .016 & 255.795 .065 & 14,9 \\
\hline UnB (b) & 90.721 .051 & 94.330 .749 & 97.739 .440 & 109.888 .416 & 21,1 \\
\hline b/a (\%) & 40,8 & 39,6 & 37.7 & 43,0 & \\
\hline
\end{tabular}

Fonte: SIAFI/SIDOR (em R \$ correntes); elaboração própria.

Desse modo, se no início do período sob análise a UNB respondia por $6 \%$ do total de gastos realizados pelas universidades federais, sob essa fonte, ao final os recursos diretamente arrecadados por ela já representavam $43 \%$ do total posto à disposição ao conjunto das universidades federais.

Conforme esclarece Amaral (2002), a expressiva redução do montante de recursos próprios, a partir de 1999, é devida à transferência dos repasses financeiros destinados à manutenção dos hospitais universitários diretamente às fundações de apoio a eles vinculadas, as quais haviam sido instituídas para essa finalidade.

Outro fator apontado por Amaral, que teria contribuído para a redução dos recursos próprios das UFs, foi o fim das aplicações finan- 
ceiras, a partir de 1995, que vinham sendo realizadas pelas IFES, com os repasses do MEC destinados ao pagamento de pessoal. Os altos índices inflacionários que prevaleceram até o início do Plano Real levaram os dirigentes das IFES, com a conivência do MEC, a incorporar os rendimentos dessas aplicações aos chamados recursos próprios.

$\mathrm{O}$ estudo sobre a UNB evidenciou, no entanto, que fatores internos à instituição teriam concorrido para a ampliação da geração de recursos próprios: (i) administração mais eficiente do patrimônio universitário; (ii) ampliação no número de parcerias realizadas com instituiçõos públicas e privadas; (iii) ampliação do número de imóveis residenciais alugados; (iv) redução dos gastos com o pagamento de dívidas mantidas com a Caixa Econômica Federal, desde a época da construção de novos prédios residenciais no campus universitário; e (v) administração centralizada da previsão da receita a ser captada pelas unidades descentralizadas.

A Universidade de Brasília teria empreendido esforços de articulação com órgãos e empresas públicas e buscado consolidar suas unidades descentralizadas como centros de excelência, voltados para a prestação de variado leque de serviços aos setores público e privado, o que teria contribuído para ampliar a captação/geração de recursos.

Apesar de todo o dinamismo em termos da captação de recursos por intermédio de fontes próprias, em certa medida como conseqüência do vasto patrimônio imobiliário que distingue a UNB das demais IFES, 2/3 do seu orçamento ainda são financiados pelo Tesouro. Além disso, parcela majoritária dos recursos arrecadados sob a forma de convênios provém de outros órgãos ou empresas públicas.

Não há dúvida de que as IFEs apresentam certa capacidade instalada de geração de recursos próprios - inclusive, que parte delas ainda explora de forma incipiente esse potencial -, tendo em vista que dispõem de pessoal altamente qualificado e, em alguns casos, de infraestrutura e equipamentos sofisticados. Além do mais, a manutenção básica de seus quadros técnicos já está assegurada de forma legal e efetiva pela União. Apesar disso, entende-se que essa capacidade de geração de recursos, por ser relativa, não seria suficiente para suprir o conjunto de demandas das IFES, em substituição aos aportes governamentais. Neste sentido, os recursos do Tesouro devem ser vistos, inclusive em longo prazo, como imprescindíveis à sobrevivência não só 
Financiamento e democratização do acesso à educação superior no Brasil...

da UNB, mas principalmente do conjunto das IFES, quando se tem em mente a preservação de seu caráter público e gratuito.

Além de a capacidade de geração de recursos próprios encontrar limites nas demandas de mercado, há também que se questionar a legitimidade da utilização dos recursos humanos mantidos pelo poder público para o exercício (remunerado) de funções estranhas àquelas que integram o tripé universitário: ensino, pesquisa e extensão. A objeção tem como fundamento, sobretudo, as implicações desse "desvio" para o cumprimento da missão universitária.

As principais alegaçōes quanto à geração de recursos próprios originam-se no movimento docente, por intermédio de suas associações, e se dirigem, sobretudo, às fundações de apoio vinculadas às IES públicas. São questionados, por exemplo, dois aspectos: i) a perda de controle das IES públicas sobre as fundações a elas vinculadas, na medida em que estaria havendo falta de transparência na gestão dos recursos financeiros gerados por algumas dessas fundações; e ii) o possível descomprometimento de docentes e servidores técnico-administrativos com relação ao cumprimento da missão universitária.

Em recente fórum realizado pela Associação dos Docentes da UNB (ADUNB), discutiu-se, entre outros temas, a finalidade das atividades pagas em instituições públicas gratuitas. De acordo com Dal Rosso (2002), algumas das atividades estariam sendo levadas a efeito sob a forma de iniciativas acadêmicas, a exemplo dos mestrados profissionalizantes, ao passo que outras seriam rotuladas de extensão universitária. Dal Rosso também critica a atuação de professores e servidores em atividades que estariam desvirtuando as finalidades básicas das instituições públicas de ensino superior, para as quais teriam sido contratados.

Se a ampliação e diversificação das iniciativas de captação de recursos próprios pelas IFES, que se acentuaram desde o início da década de 1990, decorrem, por um lado, do desejo legítimo de conferir maior celeridade à gestão institucional, por outro, também podem ser vistas como tentativas, veladas ou não, do que alguns denominam "privatização" da universidade pública. Ainda não tivesse sido essa a motivação a orientar a ação governamental na maior parte daquela década, o que não se pode negar é que as IFEs foram submetidas a profundo corte orçamentário, em especial no período 1995/1998. 
A contenção orçamentária gerou impactos sobre todas as esferas da vida acadêmica, a começar pelo achatamento salarial de quadros técnicos altamente qualificados, passando pelo corte de recursos necessários ao funcionamento e atingindo a própria infra-estrutura física e tecnológica dessas instituiçōes.

Neste sentido, a busca de fontes alternativas de recursos pode ser vista como iniciativa de sobrevivência institucional que permitiu às IFES com mais larga tradição na produção do conhecimento assegurar, em diferentes níveis e graus, a manutenção de seus quadros técnicos, o cumprimento de suas funções essenciais e a reposição e/ou aquisição de equipamentos.

Independentemente das razões que fomentaram o crescimento das iniciativas voltadas à geração de recursos próprios pelas IFES, há de se reconhecer que, a exemplo do que ocorre atualmente na Universidade de Brasília, essa fonte de financiamento tem sido imprescindível para assegurar o próprio funcionamento da instituição. Além disso, pode ser vista como parte do cotidiano institucional, na medida em que tem propiciado significativa complementação de renda para parcela considerável de seus servidores, sejam eles docentes ou técnico-administrativos.

Sob uma política governamental em que se permitiu a abertura de precedentes para soluções isoladas e casuísticas, a ocorrência de desvirtuamentos e distorções emerge como desdobramento possível. Em outras palavras, na ausência de uma ação governamental que equacionasse de forma adequada a questão do financiamento das IEs públicas, a comunidade acadêmica foi buscar soluções que contemplassem, ao menos parcialmente, demandas não atendidas.

Apesar das causas explicativas de tal prática, não se pode aceitar a legitimação sumária do conjunto dessas iniciativas instituídas, uma vez que há casos, a exemplo do que ocorre com algumas das fundações de apoio, que suscitam maior acompanhamento, fiscalização e controle por parte das instituiçóes às quais se vinculam, inclusive para efeito da sobrevivência dessa fonte complementar de recursos como mecanismo legítimo a ser empregado para o cumprimento da missão universitária.

\section{Primeiros passos da reforma da educação superior}

O processo de reforma da educação superior desencadeado pelo MEC, a partir de 2003, sob a denominação Universidade do Século XXI, 
Financiamento e democratização do acesso à educação superior no Brasil...

estaria orientado pela necessidade de democratizar o acesso a esse nível de formação e de inserir a universidade no projeto de desenvolvimento nacional. Neste sentido, algumas açōes emergenciais já têm sido desenvolvidas, no intuito de reverter o estado de deterioração ao qual foram submetidas as IFES nos últimos anos, tais como a autorização para a realização de concursos para professores, o reajuste dos valores correspondentes às bolsas de mestrado e doutorado e a negociação salarial com os docentes e servidores técnico-administrativos.

Uma das primeiras iniciativas governamentais que integram esse projeto de reforma é a que institui o Programa Universidade para Todos (PROUNI). Recentemente lançado pelo MEC, tem por objetivo contribuir para ampliar o acesso à educação superior daqueles que, pelas vias regulares, dificilmente teriam acesso a essa formação.

Trata-se de programa de concessão de bolsas de estudo destinadas a pessoas com renda familiar per capita de até um salário mínimo, nãoportadoras de diploma de curso superior e que tenham cursado integralmente o ensino médio em escolas públicas, e a professores da educação básica das redes públicas de ensino.

A instituição de ensino que aderir ao Programa deverá conceder uma bolsa de estudo para cada nove estudantes regularmente matriculados, respeitando-se tal proporção com relação aos cursos oferecidos, aos turnos e à unidade administrativa da IES. A seleção dos bolsistas também deverá beneficiar negros e indígenas em igual proporção à sua participação no conjunto populacional.

Com a adesão ao Programa, a IES participante ficará isenta do recolhimento de impostos e tributos incidentes sobre as receitas provenientes das atividades desenvolvidas na educação superior.

O projeto também institui regras mais rígidas para as IES enquadradas como beneficentes. Nesse caso, a manutenção desse status demandará a concessão de uma bolsa de estudo para cada quatro estudantes regularmente matriculados, sendo que os beneficiados deverão ter o mesmo perfil a ser adotado no caso anterior. Dessa forma, a isenção de impostos prevista pela Lei n. 9.532/95 assim como o credenciamento da IES no Programa de Financiamento Estudantil (FIES) ficarão condicionados à adesão ao PROUNI.

A principal crítica dirigida a essa iniciativa governamental é a de que os recursos que deixarão de ser arrecadados com a isenção de im- 
postos poderiam ser aplicados na ampliação da oferta de vagas nas instituições públicas. Portanto, para alguns críticos da proposta, o Estado estaria comprando vagas já existentes e ociosas, e ao mesmo tempo oferecendo um serviço de qualidade duvidosa. Por sua vez, os dirigentes do MEC argumentam que o grau de evasão fiscal nesse nível de atividade empresarial é tão elevado que aquilo que se deixaria de arrecadar seria irrisório comparado com o benefício que a ampliação do acesso à educação superior poderia oferecer.

Outro projeto que se insere na esteira da democratização do acesso é o que trata da instituição de um sistema especial de cotas, pelo qual ficariam reservados $50 \%$ das vagas das IFES a estudantes que tenham cursado todo o ensino médio em escolas das redes públicas. $\mathrm{O}$ projeto ainda estabelece que a cota de vagas deverá ser distribuída em conformidade com a composição étnica da população da unidade federada onde se localiza a instituição de ensino. No caso de não serem preenchidas todas as vagas, as remanescentes serão revertidas em favor dos estudantes oriundos de escolas públicas.

Apesar de os egressos do ensino médio nas redes oficiais já representarem mais de $40 \%$ do total de matriculados nas IES públicas, a inclusão da variável raça aumenta as chances de ingresso de estudantes dos estratos de renda mais baixos. Porém, ao deixar de considerar a renda familiar, corre-se o risco de favorecer estudantes, brancos ou nãobrancos, com perfil socioeconômico semelhante ao de parcela daqueles oriundos das escolas privadas. Se isso se confirma, compromete-se o objetivo de democratizar o acesso a estudantes social e economicamente desfavorecidos, contido no projeto de reserva de vagas nas IFES.

Essas iniciativas pontuais se inserem no projeto maior de reforma da educação superior, cujos debates iniciais remontam ao primeiro ano do Governo Lula, quando foram realizados diversos seminários que visaram a discutir a questão universitária. Com a nova equipe ministerial, empossada em janeiro de 2004, instituiu-se o Grupo Executivo da Reforma da Educação Superior, cuja atribuição seria a de elaborar um anteprojeto e submetê-lo à apreciação da sociedade. Para se chegar ao documento-base, foram colhidos subsídios por intermédio de diversos eventos (colóquios, seminários, oitivas, reuniões e debates). A partir de então, foram programadas cinco audiências públicas, nas quais o referido documento seria discutido com a sociedade. 
Financiamento e democratização do acesso à educação superior no Brasil...

De acordo com o MEC, a reforma da educação superior estaria orientada por três objetivos: i) refinanciar a universidade pública; ii) transformar a universidade pública em referência para toda a educação superior; e iii) estabelecer nova regulação entre os sistemas público e privado.

Como toda mudança, e a despeito das melhores intençóes que possam ter seus proponentes, a reforma da educação superior também vem encontrando focos de resistência, sobretudo no âmbito das associações de servidores das IFES e do movimento estudantil.

Pelas diretrizes já anunciadas e pelos procedimentos que têm sido adotados, a proposta atual de reforma distingue-se de iniciativas anteriores. No primeiro caso, ao reconhecer que a democratização desse nível de ensino não se reduz à mera expansão da oferta de vagas e, ao mesmo tempo, ao atribuir à instituição universitária papel central no processo de desenvolvimento nacional. Quanto aos procedimentos adotados, são válidas as tentativas de envolvimento da sociedade civil e, particularmente, da comunidade acadêmica no conflitante processo de reforma da educação superior.

\section{Considerações finais}

Com o esgotamento do desenvolvimentismo autoritário, em fins dos anos de 1970 , tem início a chamada década perdida. A estagnação da atividade econômica que prevaleceu, ao longo dos anos de 1980, teve como reflexo imediato a desaceleração da expansão da educação superior. No âmbito das IFES, houve redução de $0,5 \%$ no total de matrículas em cursos de graduação, no período 1980-1989. Não muito diferente, o crescimento de apenas 5,6\% no total de matriculados nas IES privadas, no mesmo período, também evidencia os efeitos da recessão econômica sobre o poder de compra desse serviço pelas famílias. Esse entendimento é reforçado pelo fato de que nas redes estadual e municipal, onde as matrículas cresceram 53,3\% no mesmo período, a tendência foi inversa. A despeito do que se verificou com essas duas redes de ensino, que em 1989 respondiam por apenas $17,7 \%$ do total de matrículas nos cursos de graduação, as fontes de financiamento mais importantes mostraramse insuficientes para assegurar a expansão do sistema.

Apesar de a participação do setor público na oferta de educação superior não ter sido ainda mais reduzida pelo fato de as redes estadual e municipal terem registrado crescimento mais expressivo, isso também 
tem suscitado preocupações, na medida em que esses entes estatais poderiam estar deixando de investir recursos nos níveis de ensino que lhes são atribuídos como prioridades constitucionais.

Nos anos de 1990, sob a influência da onda neoliberal, os governos brasileiros optaram pela deslegitimação da educação superior pública, ainda que no discurso reconhecessem sua importância para o desenvolvimento nacional e para a inserção competitiva do país no mundo globalizado.

Tal opção fica ainda mais evidente quando se tem por referência os gastos das IFES ao longo de quase toda a década de 1990, na qual prevaleceu forte contenção orçamentária, tanto para fins de sua expansão como para sua própria manutenção.

O próprio Plano Nacional de Educação (PNE), instituído pela LDB e sancionado em 2001, teve várias metas vetadas pelo Executivo. Os vetos explicitaram as incoerências entre os discursos de campanha, inclusive a exposição de motivos que integrava o PPA 1996-1999, e as medidas efetivamente tomadas.

Apesar de no PPA 1996-1999 ter sido estabelecida como meta para esse último ano o gasto equivalente a 1,5\% do PIB em investimentos em C\&T, o que correspondia ao dobro do que se aplicava na década de 1980 , foi vetada pelo presidente da República a meta do PNE que previa triplicar os investimentos públicos em pesquisa científica e tecnológica no prazo de 10 anos. De modo semelhante, foram vetadas as metas que estabeleciam que a participação do setor público na oferta de vagas em cursos de graduação não deveria ser inferior a $40 \%$ do total e que o FIES deveria ser ampliado de modo que se atendesse $30 \%$ dos estudantes matriculados nas instituições privadas.

A agenda atual de reforma da educação superior estaria contemplando algumas das proposições vetadas. A concessão de bolsas a estudantes pertencentes aos estratos de renda mais baixos, até o limite de $10 \%$ do total de matriculados nas instituiçōes privadas, conforme estabelece o PROUNI, constitui um tipo de investimento "a fundo perdido" que poderia atingir o universo atual de beneficiários do FIES. Por sua vez, a criação de um fundo de financiamento para as IFES, que assegure a essas instituiçôes a vinculação de $75 \%$ dos recursos da União para manutenção e desenvolvimento do ensino, também recupera uma das metas do PNE vetadas no governo anterior. 
Financiamento e democratização do acesso à educação superior no Brasil...

Sob o argumento de que havia uma demanda reprimida, em grande medida relativa ao fato de que as IES públicas não vinham respondendo a contento à oferta de vagas, estimulou-se a proliferação de instituições e cursos de natureza privada, a partir de 1995, mediante a flexibilização dos requisitos para tal.

Apesar de terem sido instituídos dois instrumentos que, supostamente, acompanhariam e controlariam a qualidade dos cursos - o "Provão" e a Avaliação das Condições de Ensino dos Cursos de Graduação -, na prática, uma vez autorizado o seu funcionamento, mesmo aqueles considerados de baixa qualidade continuaram a funcionar.

Uma das implicações desse modelo de expansão adotado é que, atualmente, caminha-se para certo nível de saturação desse mercado, a qual fica evidenciada não apenas pela baixa taxa de ocupação das vagas ofertadas pela iniciativa privada como também pelos altos índices de inadimplência.

Caso fosse mantida tal orientação da política de financiamento da educação superior, alinhavada desde o início da década de 1990 e efetivamente implantada pelo Governo Fernando Henrique Cardoso, tornarse-ia de difícil cumprimento o alcance da meta estabelecida no Plano Nacional de Educação (PNE) de matricular 30\% da população de 18 a 24 anos no ensino de graduação até 2011. Para se atingir a meta, assim como várias outras contidas naquele dispositivo legal, faz-se necessário, além do crescimento econômico almejado por todos, um conjunto de medidas de políticas públicas, entre as quais uma repactuação do sistema tributário nacional que favoreça o crescimento econômico e, conseqüentemente, a ampliação dos investimentos do setor público na área educacional, bem como que promova a redistribuição da renda, de forma indireta, o que também permitiria a uma parcela da população ampliar sua capacidade de gastos com a educação.

Neste sentido, o PROUNI constitui iniciativa, ainda que tímida, de redistribuição indireta de renda, ao transferir recursos de isenção fiscal a estratos populacionais mais pobres, já que tais recursos, caso fossem arrecadados, não beneficiariam necessariamente esses grupos sociais.

Outro projeto que se insere no espectro das políticas stricto sensu de democratização do acesso à educação superior é o que institui um sistema de cotas de vagas, nas IFES, para estudantes egressos do ensino médio público, na medida em que também implica transferência indi- 
reta de renda para aqueles que se supõem pertencerem às camadas sociais menos privilegiadas.

Portanto, para que a educação possa contribuir, de fato, na redução das desigualdades sociais, tornam-se necessárias políticas ativas de financiamento que favoreçam o rompimento do círculo vicioso entre educação e renda, que se estabelece de forma tão marcante na sociedade brasileira.

\section{Recebido e aprovado em setembro de 2004.}

\section{Notas}

1. Em trabalho recente, Jorge Abrahão de Castro mostra que o Ministério da Educação sofreu perda relativa de recursos, no período 1995-2002. De um orçamento executado correspondente a $1,44 \%$ do PIB, em 1995, decresceu para 1,26\%, em 2002.

2. De acordo com dados do Censo da Educação Superior do INEP/MEC, o crescimento das matrículas no ensino de graduação nas IES estaduais, no período 1990/2002, foi de $114 \%$, ou seja, bastante superior ao das IFES (72\%). Desse modo, cerca de $50 \%$ das matrículas no setor público, nesse último ano, estavam concentrados nas esferas estadual e municipal.

3. Análise ampliada acerca dessa questão encontra-se em Castro \& Corbucci (2004).

4. De acordo com Simon Schwartzmann (2003), 50,0\% dos estudantes das IES privadas pertencem aos 10,0\% mais ricos, ao passo que nas instituiçóes públicas esse índice é de 34,4\%. Por sua vez, somente $5,4 \%$ dos estudantes das IES privadas provêm dos 50,0\% mais pobres, ao passo que nas IES públicas o porcentual é de $11,7 \%$. Dados obtidos por ocasião da realização do "Provão" 2003 corroboram os resultados desse estudo: o porcentual de estudantes participantes desse exame provenientes de famílias com renda mensal de até 3 salários mínimos foi de $26,5 \%$ nas IEs públicas e de $12,9 \%$ nas privadas. Por sua vez, o porcentual dos estudantes oriundos de famílias com renda mensal superior a 20 salários mínimos era de $12,6 \%$ nas instituições públicas e de $18,0 \%$ nas IEs privadas.

5. Em 2002, cerca de $81 \%$ dos mestrandos e $91 \%$ dos doutorandos estavam matriculados nas IES públicas.

6. Ver Corbucci (2000).

7. Ver IneP (2001).

8. Este valor, atualizado pelo IGP-DI para o ano de 1999, corresponde ao valor médio das mensalidades apresentado por Schwartzman (2000).

9. Considerando o gasto mensal per capita de R\$ 530 (atualização para janeiro de 2004, do valor de 1998, pelo IGP-DI) e um efetivo de mais de 2,4 milhões de estudantes matriculados, os gastos do setor privado somariam R \$15,3 bilhões, em 2003. No setor público, o gasto atualizado estimado para 2003 seria de $\mathrm{R} \$ 14,8$ bilhões.

10. De acordo com Schwartzman (2000), "a experiência internacional mostra - e o caso brasileiro não se constitui numa exceção - que dificilmente uma universidade que tenha pa-

Educ. Soc., Campinas, vol. 25, n. 88, p. 677-701, Especial - Out. 2004 
Financiamento e democratização do acesso à educação superior no Brasil...

drão de qualidade na graduação, pesquisa, pós-graduação stricto sensu e extensão pode se custear, apenas, com a cobrança de mensalidades. Geralmente, existem recursos públicos e de outras fontes privadas que complementam o montante necessário à manutenção de um corpo docente titulado e dedicado, assim como de funcionários preparados".

11. Ver Corbucci (2000).

12. Ver Corbucci \& Marques (2003).

13. Em 2000, 26,5\% do orçamento da UNB correspondiam aos recursos próprios, ao passo que outros 7,0\% provieram da rubrica Contratos e Convênios. Ou seja, as fontes de recursos não-ordinários corresponderam a $1 / 3$ do orçamento global dessa instituição.

\section{Referências bibliográficas}

ALMEIDA, I.C. Gastos com educação no período de 1994 a 1999. Revista Brasileira de Estudos Pedagógicos, Brasília, DF, v. 82, n. 200/202, p. 137-198, jan./dez. 2001.

AMARAL, N.C. Estado e financiamento universitário no Brasil: o fundo público federal e as instituiçōes federais de ensino superior (19892001). 2002. 230f. Tese (Doutorado) - Faculdade de Educação, Universidade Metodista de Piracicaba, Piracicaba.

ANDES. Relatório final do 22. Conad: Conselho da ANDES - Sindicato Nacional. Campo Grande: ANDES, 1990.

BRASIL. Plano Nacional de Educação. Brasília, DF: Senado Federal; UNESCO, 2001.

BRASIL. Plano Plurianual (PPA) 1996-1999: mensagem ao Congresso Nacional. Brasília, DF: MPO/MF, 1996.

CASTRO, J.A. Financiamento da educação: necessidades e possibilidades. Brasília, DF: IPEA, 2004. (mimeo)

CASTRO, J.A.; CORBUCCI, P.R. Subsídios para o debate sobre o financiamento da educação superior no Brasil. Politicas Sociais, Brasília, DF, n. 8, p. 148-153, fev. 2004.

CORBUCCI, P.R. As universidades federais: gastos, desempenho, eficiência e produtividade. Brasília, DF: IPEA, 2000. (Texto para discussão n. 752) 
CORBUCCI, P.R.; MARQUES, P.M.F. Fontes de financiamento das instituiçôes federais de ensino superior: um estudo sobre a Universidade de Brasília. Brasília, DF: IPEA, 2003. (Texto para discussão n. 999)

DAL ROSSO, S. (Org.). Fórum em defesa da universidade pública e gratuita. In: Dal Rosso, S. (Org.). Atividades pagas em universidades gratuitas: caminho para a privatização. Brasília: ADUNB, 2002.

INSTITUTO NACIONAL DE ESTUDOS E PESQUISAS EDUCACIONAIS (INEP). Relatório do grupo de trabalho sobre financiamento da educação. Revista Brasileira de Estudos Pedagógicos, Brasília, DF, v. 82, n. 200/202, p. 117-135, jan./dez. 2001.

ORGANISATION DE COOPÉRATION ET DE DEVELOPPEMENT ECONOMIQUES (OCDE). Principaux indicateurs de la science et de la technologie: édition 2002-2. Disponível em: <http://www.oecd.org> Acesso em 27 fev. 2003.

SCHWARTZMAN, J. Financiamento do ensino superior particular. Revista Estudos, Brasília, DF, n. 27, 2000.

SCHWARTZMANN, S. Ricos e pobres nas universidades. O Estado de S. Paulo, São Paulo, 9 set. 2003.

VELLOSO, J. Políticas do MEC e recursos para o ensino no Governo Collor. Educação \& Sociedade, Campinas, v. 12, n. 42, p. 256-267, ago. 1992. 